\section{IMAGE UNAVAILABLE FOR COPYRIGHT REASONS}

Scanning electron micrograph of a spore tower of the slime mould Dictyostelium discoideum. Slime moulds are a curious division of plants with many of the characteristics of animals. Magnification $\times 140$.

difficulties have been suggested, notably that the original backbone of a polynucleotide may have been related to glycerol rather than ribose, or that the polymerization of early RNA molecules was guided by a structured solid surface, perhaps a clay. But in the absence of a successful demonstration that systems of that kind would function as it is inferred they did, the question of how the RNA world began
宛 remains unanswered.

On the assumption that the starting materials for RNA synthesis (nucleosides, or nucleotides linked to a phosphorylated of sugar) come into being, their autocatalytic replication seems plausible enough. G. von Kiedrowski has demonstrated ${ }^{2}$ the autocatalytic self-replication of an analogue of a hexanucleotide, using trinucleotides as starting materials. J. Rebek has described a somewhat different scheme ${ }^{3}$.

L. Orgel at the Salk Institute has demonstrated the successful copying of polynucleotide analogues up to 14 units long ${ }^{4}$, but in a system that is unlikely to have been the one used on the early Earth because of the readiness with which the molecules cyclize and otherwise wrap up on themselves.

More than two decades of the pursuit of self-replicating RNA systems, which has brought a rich harvest of information about the conditions under which replication may occur, has nevertheless also left a sense of disappointment; no artificially devised system has proved to be simple enough to be plausible, and robust enough to suggest that, on its own, it could have triggered the emergence of life.

Some of these difficulties may be sur- mounted by more recently suggested (and demonstrated) replication devices. In May this year, for example, it was shown ${ }^{5}$ that 24-nucleotide DNA molecules could be replicated, without the intervention of enzymes, in the major groove of a DNA duplex molecule serving as a template. It remains to be demonstrated that the scheme will work for molecules of general sequence, while the use of DNA duplex molecules supposes a big step beyond the RNA world.

One obvious difficulty with studies of this kind is their inevitable assumption that the replication of informational molecules on the primaeval Earth was selfcontained, and unassisted by other chemical components of the primaeval soup. That is a stringent assumption, and probably incorrect. Even so, studies of this kind are likely to continue, not only for their own sake but because of the vivid interest of the chemical industry in ordered copolymers, which may have many advantages over existing polymer materials.

\footnotetext{
1. Joyce, G.F. Nature 338, 217-224 (1989).

2. von Kiedrowski, G., Wlotza, B. \& Helbing, J. Angew. Chem. int. Ed. Engl. 28, 1235-1237 (1989).

3. Hong, J-L., Feng, Q., Rotello, V. \& Rebek, J. Science 255, 848-850 (1992).

4. Orgel, L. E. Nature 358, 203-209 (1992)

5. Li, T. \& Nicolaou, K.C. Nature 369, 218-221 (1994).
}

\title{
Guesswork and randomness (for now at least)
}

WHAT came before the RNA world? That the first living things would not have been recognizable as such is readily accepted. They may simply have been aggregations of organic molecules which, under the illumination of sunlight, allowed the evolution of particular species, RNA molecules perhaps.

Decades ago, J. D. Bernal suggested that such processes might be sustained on the surfaces of clay particles. A newer version of that picture, due to Günter Wächtershäuser, is that the surfaces would have been minerals such as pyrite, capable of binding and polymerizing simple organic molecules fashioned from five-carbon isoprene units carrying phosphate and hydroxyl substituents ${ }^{\text {. }}$.

One virtue of the model is that, with the conversion of polymerized isoprene units into glycols, simplified cell membranes could be formed along with accumulating chemicals. Wächtershäuser describes an intermediate stage of evolution in which membranes would enclose solutions of evolving chemicals between themselves and the solid substrate beneath.

More recently, the argument has been carried further by the identification of terpenoid molecules from petroleum and other geological sedimentary deposits with chemicals known to be constituents of extant cell membranes ${ }^{2}$.

So what was the actual course of events more than 3.5 billion years ago? Detailed reconstructions of the emergence of RNA, or alternatively of isoprene-based chemicals, becomes guesswork of a kind.

So why not guess from the outset? That is the basis of the now common interest in 'molecular evolution', partly stimulated by an experiment of Spiegelman in the 1960s. The RNA gene for the replicase enzyme (a protein) of the $Q \beta$ bacteriophage was used repeatedly to replicate further copies of the viral RNA in several cycles, generating departures from the original sequence in the process. Selection for the replicase giving the most rapid replication of the whole virus eventually yielded a dramatically shorter enzyme.

Now that the production of random sequences of RNA is relatively simple (by producing random sequences of DNA in a synthesizer, and then converting them to RNA, for example) there have been demonstrations of how to evolve, with the help of a selection process, RNA molecules with particular properties - their binding to small molecules ${ }^{3}$ or their

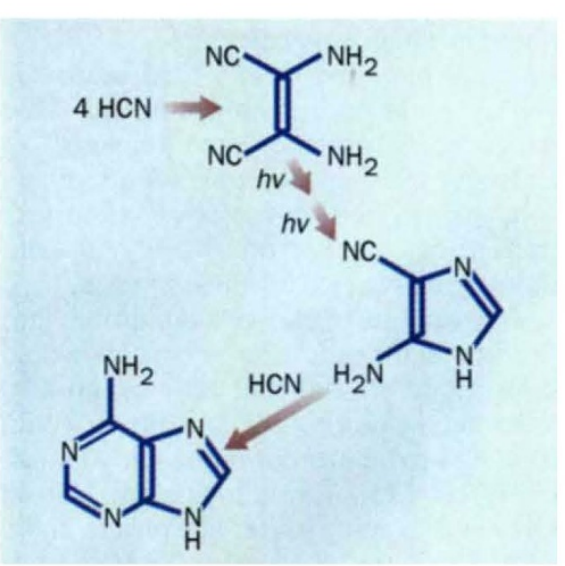

Synthesis of the nucleotide adenine (bottom left) from $\mathrm{HCN}$.

enzymatic function as ribozymes ${ }^{4}$.

The prophet of this approach is Stuart Kauffman, from the Sante Fe Institute, New Mexico. A patent originally in his name is now owned by the Darwin Institute in Seattle, Washington. Expectations among industrial molecular biologists are high. Whether the same approach will be applicable to real life is another matter.

\footnotetext{
1. Wächtershäuser, G. Microbiol. Rev. 52, 452-458 (1988).

2. Ourisson, G. \& Nakata, Y. Chem. \& Biol, 1, 11-23 (1994).

3. Ellington, A.D. \& Szostak, J.W. Nature 346, 818-822 (1990).

4. Bartel, D.P. \& Szostak, J.W. Science 261, 1411-1418 (1993).
} 